\title{
The mechanochemical processing of aerospace metals
}

\author{
F.H. Froes ${ }^{\mathrm{a}, *}$, B. Trindade ${ }^{\mathrm{b}}$ \\ ${ }^{a}$ Institute for Materials and Advanced Processes, College of Engineering, University of Idaho, McClure Hall, Room 437, Moscow, ID 83844-3026, USA \\ ${ }^{\mathrm{b}}$ Departamento de Enginharia Mecanica, Universidade de Coimbra, Polo II-3030 Coimbra, Portugal
}

\begin{abstract}
The status of mechanochemical processing of aerospace metals (aluminum and titanium) is reviewed. It is demonstrated that the activation of chemical reactions by mechanical energy can lead to many interesting applications including production of advanced materials with novel constitutional and microstructural effects leading to enhanced mechanical properties.
\end{abstract}

(C) 2004 Elsevier B.V. All rights reserved.

Keywords: Mechanochemical processing; Aerospace metals; Aluminum; Titanium; Departure from equilibrium; Nanograins

\section{Introduction}

Mechanochemical processes (MCP) use mechanical energy to activate chemical reactions and structural changes. However these are not new processes, mechanically activated processes date back to the early history of mankind, for example, the use of flints to initiate fire. Following these early uses mechanochemistry has had a rich history, particularly in Europe, which has led to the use of ball mills for processing a wide range of materials ranging from mineral to advanced materials.

Mechanochemical processing can be divided into: mechanical milling (MM), mechanical alloying (MA), and reaction milling (RA). Mechanical milling refers to the milling of a pure metal or compound which is in a state of thermodynamic equilibrium at the start of milling. Mechanical alloying, refers specifically to the formation of alloys from elemental precursors during processing in a ball mill. Reaction milling uses mechanical processing to induce chemical reactions. The principle attributes of mechanochemical processing are shown in Table 1 [1-8].

This review is based on a previous review by one of the authors [9], in the present case concentrating on the application of MCP to the aerospace metals aluminum and titanium.

\footnotetext{
* Corresponding author. Tel.: +1-208-885-7989; fax: +1-208-885-4009. E-mail addresses: imap@uidaho.edu (F.H. Froes), bruno.trindade@mail.dem.uc.pt (B. Trindade).
}

\section{Science}

Solid state reactions, whether alloying or chemical reactions, involve the formation of one or more product phases which separate the reactants. Diffusion through the product phases is invariably the rate controlling process and consequently normally high temperatures are required to achieve acceptable reaction kinetics. Mechanochemical processing overcomes this diffusion limitation, with the metastable structures developed by MCP directly reflecting the diffusion constraints imposed by the low temperature nature of the process.

The departure from equilibrium possible using MCP is shown in comparison with a number of other "far from equilibrium" processes in Table 2 (3). The departure possible using vapor phase processing is greater than that for MCP; but MCP allows greater excursion than rapid solidification (RS).

An important feature of MCP is the refinement of microstructure, i.e. grain size and particle size, associated with particle deformation, fracture and welding processes which accompany ball/powder collision events. The energy transmitted to crystalline powders during milling results in a dislocation call structure which develops into random nanostructured grains with increasing milling time. While nanometer grain sizes are developed during MCP, powder particle sizes generally decrease only to the micron level.

MCP can also result in extended solid solubility, disordering and the formation of amorphous structures. Schwarz et al. [10] have shown that such high solubility enhancements can be rationalized in terms of a metastable equilib- 
Table 1

Attributes of mechanochemical processing

\begin{aligned} & \hline 1 Mineral and waste processing \\ & 2 Refining of metals \\ & 3 Combustion reactions \\ & 4 Production of ultrafine powders \\ & 5 Production of a fine dispersion of second phase particles \\ & 6 Extension of solubility limits \\ & 7 Refinement of the matrix microstructure/nanograin formation \\ & 8 Synthesis of novel crystalline phases \\ & 9 Formation of amorphous (glassy) phases \\ & 10 Possibility of alloying of difficult to alloy elements \\ & 11 Scalable process \\ & \hline\end{aligned}

Table 2

Departure from equilibrium achieved in various processes (3)

\begin{tabular}{lc}
\hline Process & $\begin{array}{l}\text { Maximum departure } \\
\text { from equilibrium } \\
\left(\mathrm{kJ} / N_{\mathrm{a}}\right)^{\mathrm{a}}\end{array}$ \\
\hline Solid state quench & 16 \\
Quench from liquid (rapid solidification) & 24 \\
Condensation from vapor & 160 \\
Irradiation/ion implantation & 30 \\
Mechanical cold work & 11 \\
Mechanical alloying & 30 \\
\hline
\end{tabular}

${ }^{\text {a }} N_{\mathrm{a}}$ is Avogadro's number, i.e. assuming no relaxation due to kinetic effects.

rium between the solid solution and a solute rich amorphous phase.

A significant research effort has been devoted to studies of mechanically induced amorphization reactions over the past 10 years [9]. It appears that for amorphous phases to form during mechanical milling, the increase in energy of the milled powder, which is mainly due to the increased volume fraction of grain boundaries and disordering, must raise the free energy to above the level of the amorphous state $[11,12]$.

The formation of metastable crystalline phases during MCP has been reported by a number of researchers [9], for example, the formation of metastable phases during the mechanical milling of rare earth sesquisulfide phases.

\section{Technology}

\subsection{Refining of metals}

A wide variety of oxidation-reduction reactions can be activated during mechanical milling of an oxide or chloride with a suitable reductant. Examples of potentially important refining reactions include the reduction of $\mathrm{TiCl}_{4}$ (a liquid at room temperature) with $\mathrm{Mg}$, and $\mathrm{TiO}_{2}$ with $\mathrm{CaH}_{2}$ $[13,14]$. It has been shown that decreasing the milling temperature so that $\mathrm{TiCl}_{4}$ becomes solid increases the reaction kinetics by a factor of 6 , demonstrating the importance of solid-solid interactions at welded interfaces during milling [9] (Fig. 1).

\subsection{Production of second phase dispersions}

The MA process was initially developed in the late 60s to combine the intermediate temperature strength of the $\gamma^{1}$ precipitate with the high-temperature dispersion hardening in nickel-base alloys [9]. And this is presently the major commercial (350t per year) use of the process. The cost of the MA step is held proprietary by the producer (INCO) but is probably about $\$ 5 / \mathrm{lb}$ for an $8 \mathrm{~h}$ MA cycle.

Mechanical alloying of Al-base alloys leads to a higher-temperature capability than similar RS-processed materials [6-8]. The additional improvement results from the formation of fine $\mathrm{Al}_{2} \mathrm{O}_{3}$ and $\mathrm{Al}_{4} \mathrm{C}_{3}$ dispersoids which are due to the addition of organic process control additives and the presence of ambient oxygen in the milling atmosphere.

The dispersoids formed in MA'd alloys are very fine, uniformally distributed and both the grains and dispersoids do not coarsen considerably even on very high-temperature exposure to temperatures up to $1100^{\circ} \mathrm{C}$ [6-8]. Fig. 2 shows that both the grain and dispersoid sizes are much finer in the MA'd Ti 3 Al-2Er alloy even though this was hot isostatically pressed (HIP'd) at $1000^{\circ} \mathrm{C}$, a temperature $150^{\circ} \mathrm{C}$ higher than the HIP'ing temperature for the rapidly solidified (RS) alloy.
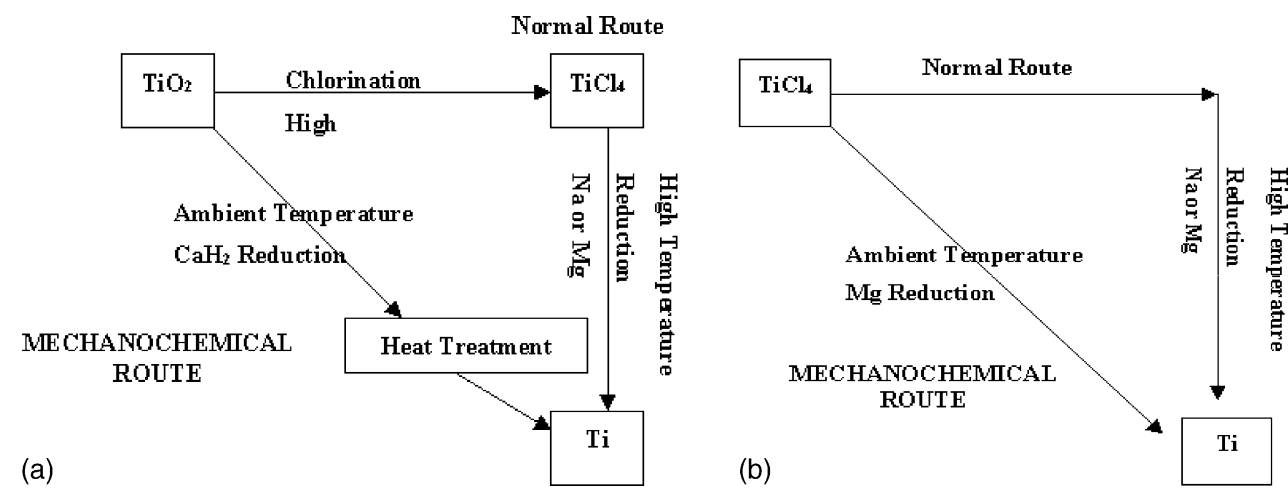

Fig. 1. Comparison of mechanochemical and conventional production of titanium from (left) $\mathrm{TiO}_{2}$ and (right) $\mathrm{TiCl}_{4}$. 


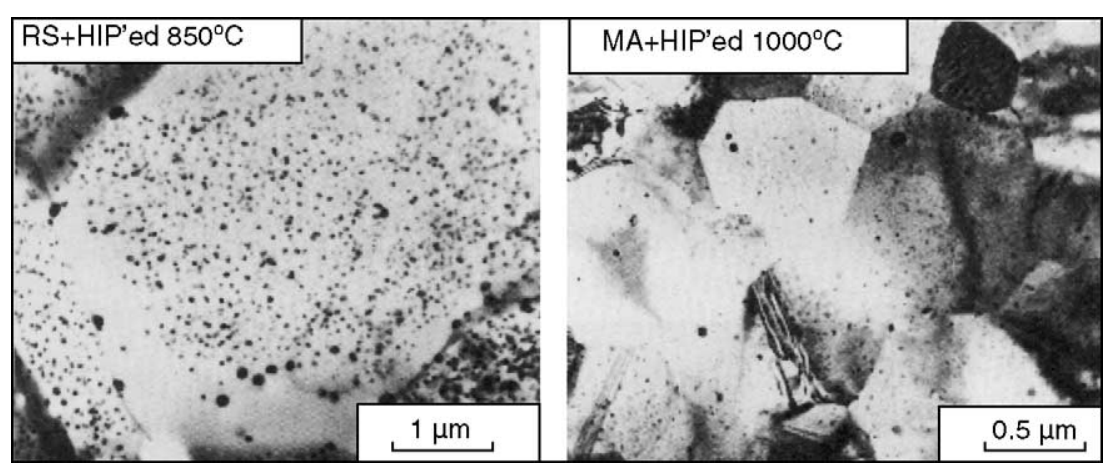

Fig. 2. Comparison of HIP'd RS (at $850^{\circ} \mathrm{C}$ ) and $\mathrm{MA}\left(\right.$ at $1000^{\circ} \mathrm{C}$ ) dispersion strengthened $\mathrm{Ti}_{3} \mathrm{Al}+2 \mathrm{Er}$.

Table 3

Solid solubility extension by mechanical alloying and rapid solidification

\begin{tabular}{llccc}
\hline Solvent & Solute & \multicolumn{3}{c}{ Solid solubility (at.\%) } \\
\cline { 3 - 5 } & & Equil. at RT & By RS & By MA \\
\hline $\mathrm{Al}$ & $\mathrm{Fe}$ & 0.025 & 4.3 & 4.5 \\
$\mathrm{Al}$ & $\mathrm{Hf}$ & 0.0007 & 0.3 & 1.5 \\
$\mathrm{Al}$ & $\mathrm{Mg}$ & 18.9 & 40 & 23 \\
$\mathrm{Al}$ & $\mathrm{Nb}$ & 0.065 & 2.4 & $>25,<30$ \\
$\mathrm{Al}$ & $\mathrm{Zr}$ & 0.015 & 1.3 & 6.3 \\
\hline
\end{tabular}

\subsection{Solid solubility extension}

Some solubility extensions in the aluminum system obtained by MA, and corresponding values developed using RS, where available, are listed in Table 3. These are the solubility levels obtained in terminal solid solutions, little data is available on the intermetallics. Mechanical alloying should generally allow even greater solid solubility extension (SSE) than RS [3].

\subsection{Nanostructured grains}

The large amount of energy transmitted to MA'd powders results in a dislocation cell structure within shear bands which transforms to random nanostructured grains with increasing MA time [9]. In the Ti-Al system, the crystal size in the MA'd powder decreased exponentially with milling time and reached nanometer levels in less than $1 \mathrm{~h}$; de- creased milling intensity (lower ball-to-powder ratio) resulted in slower decrease in the crystal size. The presence of the nanostructured grains after HIP'ing was confirmed by transmission electron microscopy (Fig. 3) [6-8].

\section{Contamination effects}

Reactive metals such as titanium can interact strongly with $\mathrm{O}_{2}, \mathrm{~N}_{2}$ and $\mathrm{H}_{2}$. This high reactivity combined with the small particle size and large surface areas generated by MCP requires considerable care and attention during powder handling and milling to avoid contamination of the materials being processed. Contamination from the grinding media and milling container is also a concern. Several studies have shown that features including the phases present and solubility extension can be influenced by inadvertent reaction with oxygen and nitrogen during milling [9]. However, provided sufficient attention is paid to sealing and powder handling procedures the pickup of impurities during milling and subsequent heat treatment can be held at acceptable levels.

\section{Conclusions and future trends}

The use of MCP in chemical refining allows the direct synthesis of metals and alloys without the need for heating. In principle MCP allows the three processes, refining, alloying and powder manufacture, to be carried out in a single low

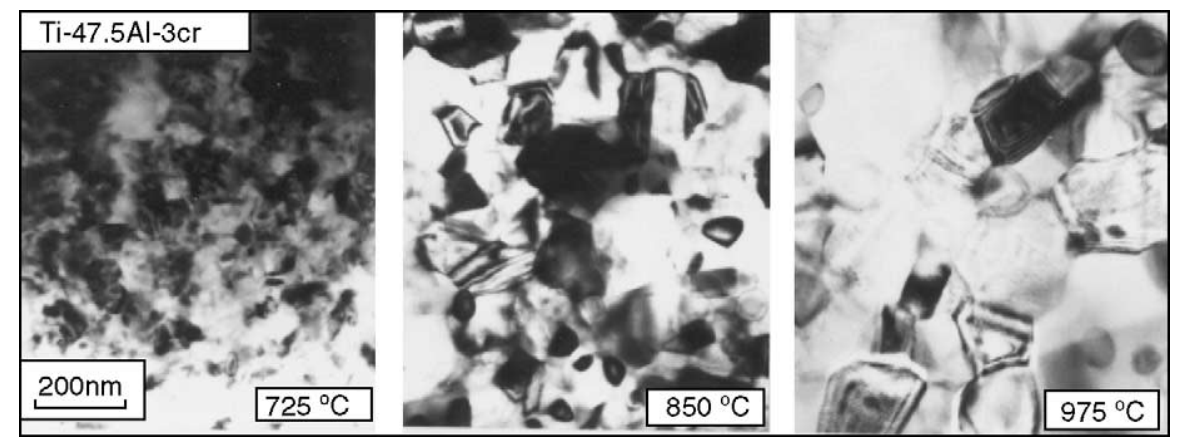

Fig. 3. Stability of grain structure in a hot isostatically pressed gamma titanium aluminide. 
temperature process. However in practice, attention must be given to handling and further processing go highly reactive as-milled powders and the removal of reaction by-products. Much creative work is possible here.

Studies of the MCP of advanced materials include consideration of nanostructured grains, metastable nanocrystalline and amorphous phases, can be synthesized. The ability to alloy and form phases at low temperatures without melting or high-temperature processing is a unique feature of mechanically activated processing. The low temperature nature of the process enables disordering and amorphization to occur with the resulting structures being determined by kinetic rather than thermodynamic considerations. Low temperature heat treatment of MA'd structures can also result in the formation of new non-equilibrium phases due to the kinetic constraints of diffusion.

Thus the MCP approach is a potential useful processing/synthesis technique is a variety of areas. Whether this approach will mature to commercialization, beyond the current ODS superalloys, will depend on property improvement levels and cost; the latter factor estimated at \$ 5/lb for the MA'ing step for production of the ODS superalloys.

\section{Acknowledgements}

The authors acknowledge useful discussion with their colleagues including E.G. Baburaj, J.J. DeBarbadillo, G.B. Eranezhuth, P.S. Goodwin, C.C. Koch, P.G. McCormick, S. Patankar, R. Schwarz, F. Sun, T. Tsuzuki, C.M. Ward-Close and D. Zhang. We would also like to thank Ms. Marlane
Martonick and Holly Palmer for their help in manuscript preparation.

\section{References}

[1] R. Sundareson, F.H. Froes, JOM 39 (8) (1987) 22.

[2] F.H. Froes, J.J. deBarbadillo, C. Suryanarayana, in: F.H. Froes, J.J. deBarbadillo (Eds.), Structural Applications of Mechanical Alloying, ASM Int., Materials Park, OH, 1990, p. 1.

[3] F.H. Froes, C. Suryanarayana, K.C. Russell, C.M. Ward-Close, in: J. Singh, S.M. Copley (Eds.), Proceedings of the International Conference on Novel Techniques in Synthetics and Processing of Advanced Materials, TMS, Warrendale, PA, 1995, p. 1.

[4] I.S. Polkin, F.H. Froes, Int. J. Mater. Product Technol. 10 (1-2) (1995) 106.

[5] C.M. Ward-Close, F.H. Froes, JOM (1994) 28.

[6] F.H. Froes, in: Proceedings of the Conference ICAMP-2000 on Advanced Materials Processing, Hamilton, New Zealand, November 2000.

[7] F.H. Froes, in: Proceedings of the Conference ICAMP 2002 on Developments in the Synthesis, Processing and Applications of Lightweight Metallic Materials, Singapore, December 2002.

[8] F.H. Froes, Cost Effective Synthesis, Processing and Applications of Light-weight Metallic Materials, TMS, Seattle, WA, February 17-21, 2002.

[9] P.G. McCormick, F.H. Froes, JOM 50 (11) (1998) 61.

[10] R.B. Schwarz, R.R. Petrich, C.K. Saw, J. Non-Cryst. Solids 76 (1989) 281.

[11] C.C. Koch, Ann. Rev. Mater. Sci. 19 (1989) 121

[12] J.S.C. Jang, C.C. Koch, J. Mater. Res. 5 (1990) 498.

[13] P.G. McCormick, V.N. Wharton, M.M Reyhani, G.B. Schaffer, in: D.C. Van Aken, G.S. Was, A.K. Ghosh (Eds.), Microcomposites and Nanophase Materials, The Metallurgical Society, Warrendale, PA, 1991, p. 65.

[14] F.H. Froes, B.G. Eranezhuth, K. Prisbrey, Mechanochemical processing for metals and metal alloys, US Patent No. 6,231,636 B1 (May $15,2001)$ 